\title{
Changing attitudes, improving lives
}

\author{
Elizabeth Loder head of research
}

The BMJ

Palliative care has an image problem: patients and families have negative views about receiving it, and those who need it commonly enter care reluctantly or too late. Boyd and colleagues (doi:10.1136/bmj.1881) discuss whether these unfavourable ideas might improve if palliative care were rebranded, perhaps as "enhanced" or "best supportive care." The term "end of life care" is not optimal, because palliative interventions are helpful, and should be introduced, well before the end of life. Ultimately the authors conclude that attitudes, not names, should change. But they acknowledge that positive language matters. Rather than describing palliative care as an end of life intervention, doctors and families should instead consider it "an opportunity for specialist advice on managing pain and other symptoms, for help with complex decision making, and in preparing for the future."

Opt-out presumed consent systems for organ donation are a tricky sell. In this week's Head to Head, Blair Sadler and Arthur Sadler Jr (doi:10.1136/bmj.1967) say that opt-out systems have superficial appeal but evidence that they result in higher donation rates is "weak and unpersuasive." The way forward, they say, is better education of the public and better training for the medical staff who approach families about donation. Conversely, Veronica English and Emma Johnson say that opt-out systems do work and cite early and encouraging evidence from Wales, which adopted such a system in 2015. But they are careful to point out that opt-out systems are only one part of a more comprehensive strategy that includes public campaigns designed to change attitudes about organ donation; in fact, they say, the legislation itself "acts as a catalyst" for investment in publicity and education about the need for organ donors. And in a patient commentary, Erin Walker, currently on her third liver, describes how she got her life back after transplantation (doi:10.1136/bmj.11004).

Attitudes to guns and laws regulating their possession vary considerably among US states. Reeping and colleagues (doi:10. $1136 / \mathrm{bmj} .1542$ ) used time series analysis to evaluate the association between the strictness of gun laws and mass shootings, defined as events in which four or more people were killed. For every 10 unit increase in state gun law permissiveness they found an almost $12 \%$ rise in the rate of mass shootings. The researchers point to a growing divide in recent years between restrictive and permissive states, with mass shootings decreasing in states with restrictive laws and increasing in those where laws are more permissive.

The BMJ is pleased to align itself with the TIME'S UP Healthcare movement, which seeks to create awareness of gender inequality and harassment in the medical workplace. But, say Rhonda Acholonu and colleagues (doi:10.1136/bmj. 1987), awareness isn't enough. Attitudes must change and systemic solutions be sought. Making things better for doctors will also help patients, as diversity leads to improved care and physicians who better reflect the populations they serve. 